\title{
High-Sensitivity Metal Oxide Sensors Duplex for On-the-Field Detection of Acetic Acid Arising from the Degradation of Cellulose Acetate-Based Cinematographic and Photographic Films
}

\author{
Daniele Zappi ${ }^{1,2}{ }^{\mathbb{D}}$, Gabriele Varani ${ }^{1}$, Igor Iatsunskyi ${ }^{3} \mathbb{D}$, Nadja Wallaszkovits ${ }^{4}$, Josef Bailer ${ }^{5}$ \\ and Maria Teresa Giardi 1,2,* \\ 1 Biosensor Srl, Via Degli Olmetti 44, Formello, 00060 Rome, Italy; daniele.zappi@ic.cnr.it (D.Z.); \\ g.varani@biosensor.it (G.V.) \\ 2 Istituto di Cristallografia, CNR Area Della Ricerca di Roma, Monterotondo Scalo, 00015 Rome, Italy \\ 3 NanoBioMedical Centre, Adam Mickiewicz University, Wszechnicy Piastowskiej 3, 61-614 Poznań, Poland; \\ igoyat@amu.edu.pl \\ 4 Phonogrammarchiv, Aiustrian Academy of Sciences, Liebiggasse 5, 1010 Vienna, Austria; \\ Nadja.Wallaszkovits@oeaw.ac.at \\ 5 Labor Erich Schmid, Austrian Academy of Sciences, Rötzergasse 57, 1170 Vienna, Austria; \\ Joseph.Bailer@univie.ac.at \\ * Correspondence: mt.giardi@biosensor.it
}

check for updates

Citation: Zappi, D.; Varani, G.; Iatsunskyi, I.; Wallaszkovits, N.; Bailer, J.; Giardi, M.T.

High-Sensitivity Metal Oxide Sensors Duplex for On-the-Field Detection of Acetic Acid Arising from the Degradation of Cellulose Acetate-Based Cinematographic and Photographic Films. Chemosensors 2022, 10, 60. https://doi.org/ $10.3390 /$ chemosensors 10020060

Academic Editors: Bilge Saruhan-Brings, Roussin Lontio Fomekong and Svitlana Nahirniak

Received: 27 December 2021

Accepted: 29 January 2022

Published: 1 February 2022

Publisher's Note: MDPI stays neutra with regard to jurisdictional claims in published maps and institutional affiliations.

Copyright: (C) 2022 by the authors. Licensee MDPI, Basel, Switzerland. This article is an open access article distributed under the terms and conditions of the Creative Commons Attribution (CC BY) license (https:// creativecommons.org/licenses/by/ $4.0 /)$
Abstract: In this work, a system consisting of two resistive sensors working in tandem to detect and quantify the acetic acid released during the degradation of cellulose acetate-based ancient cinematographic and photographic films is presented. Acetic acid must be constantly monitored to prevent reaching concentrations at which autocatalytic degradation processes begin. The sensors are constituted by a thin layer of metal oxide (tungsten oxide and tin oxide) deposited over an interdigitated electrode capable of being heated, chosen to maximize the array response towards acetic acid vapors. The signals obtained from the sensor array are mathematically processed to reduce the background signal due to interferent gases produced during degradation of ancient cinematographic films. The sensor array reported a LOD of $30 \mathrm{ppb}$ for acetic acid, with a linearity range up to $30 \mathrm{ppm}$. Finally, the sensor array was tested with different cinematographic and photographic film samples made of cellulose acetate, whose degradation state and acetic acid production was validated using the conventional technique (A-D strips). The presented array is suitable for remote monitoring large number of films in collections since, compared to the official technique, it has a lower detection limit (30 ppb vs. $500 \mathrm{ppb}$ ) and is much quicker in providing accurate acetic acid concentration in the film boxes (15 min vs. $24 \mathrm{~h}$ ).

Keywords: metal oxide semiconductor sensors; cultural heritage protection; cellulose acetate; cinematographic films; autocatalytic degradation; acetic acid; butanol

\section{Introduction}

Cultural heritage $(\mathrm{CH})$ preservation is nowadays understood as a two-phase action: on one hand, it consists of restoring and recovering damaged $\mathrm{CH}$ elements; on the other hand, increasing attention is directed to monitoring the parameters responsible for the $\mathrm{CH}$ artifacts' degradation.

A new emerging problem in $\mathrm{CH}$ preservation regards the phenomena of degradation caused by compounds produced by the $\mathrm{CH}$ items themselves. This problem is particularly complicated for numerous factors: compounds to be monitored depend on the nature of the $\mathrm{CH}$ item [1-3]. Even objects of the same general type may produce different compounds depending on specific previous treatments and restorations performed on them. Harmful 
compounds released by the $\mathrm{CH}$ item are often mixed with numerous other released substances; thus, specific sensors must be used. Harmful compounds must be detected at the onset of the process, meaning low detection limits are required for the sensor.

Environment condition monitoring is also critical to ensure that sensors and measuring devices can perform satisfactorily. The conditions to be monitored are temperature, pressure, humidity of measured gas representing the main parameters to monitor in museums in order to establish the conservation status of $\mathrm{CH}$ objects.

A case of application is the preservation of historical photographical and movie films. $\mathrm{CH}$ movie films can go as back as early the beginning of the 20th century while photographic films can date to even earlier. Both movies and photographic films used cellulose esters as support on which the photosensitive compounds were applied. The two main cellulose esters used (in order of time) were cellulose (di and tri) nitrate and cellulose (poly)acetate. Both polymers have good flexibility and mechanical resistance but over time they undergo various degradation processes that makes them rigid, brittle and, finally, unsuitable for reproduction and/or visualization. The two types of film polymer undergo different degradation pathways, meaning that sensors selective for different compounds are needed.

Cellulose nitrate is a common semi-synthetic plastic film, formally known as "celluloid", and was widely used until 1940 when it started to be phased out in favor of cellulose (poly)acetate.

Cellulose acetate is another very common semi-synthetic plastic film. Its use in both cinematographic and photographic films started around 1930 and completely supplanted celluloid between 1940 and 1950. Cellulose acetate consists of linear cellulose polymers in which each glucose monomer has two or three -OH groups functionalized as acetate ester [4,5]. Triphenyl phosphate is the most common plasticizer used for acetate films in quantities from 5-25\% by weight of the cellulose ester [6-9]. The degradation of cellulose acetate is a two-stage process: in the first step, water from air humidity promotes the breakage of an ester bond between glucose and an acetate group. The product of this step is a (n-1) acetate glucose and an acetic acid molecule. The second step of the degradation involves the acetic acid produced in the first step: a sufficiently high concentration of acetic acid will start an autocatalytic breakage process of the glucose-acetate ester bond. This process will become autocatalytic, resulting in a rapid degradation of the film once threshold concentrations of acetic acid are reached [10-12]. If the cellulose acetate film is put in a storage where there is already a high concentration of acid vapors (i.e., the presence of already degraded cellulose acetate films), the degradation process can immediately move to the second phase, with a very high degradation speed. It is thus very important to frequently monitor both the degradation state of the cinematographic films and their possible acetic acid contamination due to storage near already degraded films.

The current recognized technique to measure acetic acid produced during film degradation is by using A-D strips. These are small paper strips, soaked with an acid-base indicator, which shift in color from blue, through shades of green and finally yellow in the presence of increasing amount of acetic acid $[13,14]$. Although these strips allow a rough evaluation of the degradation state of the film, they depend strongly on the operator interpretation (acetic acid concentration is calculated by comparing A-D strip color to a provided reference) and make it difficult to monitor the ongoing conditions of very large film collections.

In this work, we present an alternative, innovative solution for monitoring the conditions of cellulose-based films by quantifying the acetic acid released during degradation. A metal oxide semiconductor (MOS) sensors duplex has been assembled, testing different commercially available resistive MOS sensors, optimizing the sensor choice in order to create a sensing duplex capable of selectively quantifying acetic acid coming from cellulose acetate cinematographic films degradation. MOS-type sensors were chosen since numerous literature sources reports them as having low limit of detection, being quite selective for their target gas(es) and having extremely low energy and space requirements compared 
to other detection tools having similar analytical properties [15-17]. These last points are of particular interest for the case discussed here, since the developed sensing solution aims to be integrated directly into old cinematographic film boxes in order to provide real-time estimation of the undergoing degradation. The sensor duplex was tested first against known concentrations of acetic acid and with the main secondary released vapor, as found with SPME-GC/MS measurements, and finally with real cinematographic film samples. The results were validated by comparison with those obtained employing the official degradation level determination system for cellulose acetate cinematographic films, A-D strips. Finally, software was written to automatically acquire data from the sensing array, display them both in numerical and graphical form, and perform calculations to determine the acetic acid concentration regardless of interferents. The obtained system can thus remotely monitor the degradation level of cellulose acetate-based films by quantifying the acetic acid present in the film box, allowing for sensitive (30 ppb detection limit vs. $500 \mathrm{ppb}$ of A-D strips), fast (10-min incubation in the box vs. 24+ hours with A-D strips) and safe (no exposure of human operator to gasses accumulated in the box during storage) cinematographic films monitoring and preservation.

\section{Materials and Methods}

\subsection{Materials}

Materials used in this study are ethanol, pure acetic acid (98\%), acetone, methyl chloride, 1-butanol, purchased from Sigma Aldrich (St. Louis, MO, USA). Metal Oxide Semiconductor (MOS) sensors were bought from Figaro USA, Inc. (Figaro USA, Inc. Arlington Heights, IL 60005 USA), electrical components were bought from RS Components S.r.l (RS Components S.r.l Sesto San Giovanni, Milan, Italy). Arduino Board UNO was bought from Italian Arduino Authorized Distributor (Melopero S.r.l., Rome, Italy). Milli-Q water was used in all experiments that required sample dilution.

\subsection{Scanning Electron Microscopy and Raman Spectroscopy}

Morphology and chemical properties of selected sensors were studied by scanning electron microscopy (SEM, JEOL, Tokyo, Japan), JEOL JSM'7001F (JEOL, Tokyo, Japan) with energy-dispersive $X$-ray analysis (EDX). To study the phase of thin-layer metal oxides, Raman spectroscopy (Renishaw micro-Raman spectrometer, Renishaw, Wotton-underEdge, England) was used. The Raman spectra were excited by a $633 \mathrm{~nm}$ laser with a power $0.5 \mathrm{~mW}$.

\subsection{Mathematical Data Processing and Gas Concentration Calculation}

All mathematical systems used to process the data produced by the assembled MOS sensor duplex and the codes used to calculate acetic acid concentration were written using the GNU language R.

\subsection{Evaluation of Film Degradation by Colorimetric Paper Strips}

A-D Strips (RIT Image Permanence Institute, Rochester Institute of Technology/IPI, Rochester, NY, USA) are small paper strips imbibed with a chemical that changes color upon exposition to acid vapors. These strips are considered the official methodology to evaluate the degradation level of cellulose acetate-based films [18]. The evaluation is performed as follows: one A-D strip is put inside the box containing the film to evaluate its degradation level. The box is closed and at least $24 \mathrm{~h}$ are allowed to pass (depending on storage temperature of the film, film stored in refrigerated rooms will require longer incubation times). The strip is then recovered, and its color is compared to a reference to evaluate the degradation level of the film. The color will vary from blue (level 0) corresponding to no significant degradation, up to bright yellow (level 3) corresponding to almost completely degraded films. It is possible to calculate the amount of acetic acid released by the film sample by using the conversion table provided with the A-D strips [18]. 


\subsection{Sample Selection}

A total of 48 film and photographic reels made of cellulose acetate were selected for testing. Three further reels, made of different materials (i.e., polyester-PET, cellulose nitrate), were added to act as negative controls for the test. For each sample, the degradation level and corresponding acetic acid concentration were determined using A-D strips. The samples chosen are reported in Table 1, along with information provided by the owner, degradation level determined by means of A-D strips, and corresponding acetic acid concentration in the film box [18].

Table 1. Real film samples used in this work. For each are reported information provided by the owner, A-D strip level. Films marked with ${ }^{\text {a }}$ are made of PET instead of cellulose acetate.

\begin{tabular}{|c|c|c|c|}
\hline Owner/Code & Film Name & A-D Strip Level & $\begin{array}{c}\text { Acetic Acid } \\
\text { Concentration (ppm) }\end{array}$ \\
\hline \multicolumn{4}{|c|}{ Fondazione Alinari Per La Fotografia } \\
\hline Alinari sample 0 & 3 photos: Construction site & 2.5 & 18.0-20.0 \\
\hline Alinari sample 1 & Photo of office & 0 & $\leq 0.5$ \\
\hline Alinari sample 2 & Photo of industrial machinery shop & 0 & $\leq 0.5$ \\
\hline Alinari sample 3 & Photo of electrical equipment & 0 & $\leq 0.5$ \\
\hline Alinari sample 4 & Technical specification for equipment & 0.5 & $0.5-1.0$ \\
\hline Alinari sample 5 & Various symbols on pentagram & 0.5 & $0.5-1.0$ \\
\hline Alinari sample 6 & Photo of office reception & 0.5 & $0.5-1.0$ \\
\hline Alinari sample 7 & Photo of art piece & 0.5 & $0.5-1.0$ \\
\hline Alinari sample 8 & 3 photos: 1 people dining, 2 and 3 press conference & 0 & $\leq 0.5$ \\
\hline Alinari sample 9 & Photo of building & 1 & $1.0-2.0$ \\
\hline Alinari sample 10 & Photo of Italian street & 1 & $1.0-2.0$ \\
\hline Alinari sample 11 & 2 photo reels: column and archeological pieces & 0 & $\leq 0.5$ \\
\hline Alinari sample 12 & 3 photos: TV show & 0 & $\leq 0.5$ \\
\hline Alinari-B/W photo films & $\begin{array}{c}5 \text { photos: } 1 \text { inside of office, } 2 \text { outside of historical } \\
\text { building, } 3 \text { inside of restaurant, } 4 \text { man admiring } \\
\text { paintings, } 5 \text { people discussing }\end{array}$ & 0.5 & $0.5-1.0$ \\
\hline Alinari-B/W photo reel & 3 photos: official meeting & 1 & $1.0-2.0$ \\
\hline Alinari-red hue photo films & $\begin{array}{c}3 \text { photos: } 1 \text { airplane storage, } 2 \text { and } 3 \text { photos inside } \\
\text { homes at Christmas }\end{array}$ & 0.5 & $0.5-1.0$ \\
\hline Alinari-color photo film & Photo of Pantheon-Rome & 0.5 & $0.5-1.0$ \\
\hline \multicolumn{4}{|c|}{ Institut Valencià De Cultura (Filmoteca Valenciana) } \\
\hline 00010820 & Publicidad Rico Famosa & 3 & $>20$ \\
\hline 00011242 & Febus Comic 4 Publicidad & 0.5 & $0.5-1.0$ \\
\hline 00015797 CulturArts 5 & "Easy street" (Charlot en la calle de la tranquilidad) & $2-2.5$ & $8-18$ \\
\hline 00015798 CulturArts 7 & Canario Roj & 1.5 & $3-5$ \\
\hline 00015799 CulturArts 6 & Maigret en el caso de la condesa & 0.5 & $0.5-1.0$ \\
\hline 006113 & Las Truchas & 0.5 & $0.5-1.0$ \\
\hline \multicolumn{4}{|c|}{ Deutsches Filminstitut \& Filmmuseum } \\
\hline DFF_12_21 & Das Wachsfigurenkabinett & 0 & $\leq 0.5$ \\
\hline DFF_12_556 & Nosferatu & 0 & $\leq 0.5$ \\
\hline DFF_12_584 & Das Lied der Nachtigall & 0 & $\leq 0.5$ \\
\hline DFF_3.01.35.01 & Fire & 0 & $\leq 0.5$ \\
\hline DFF_3.01.35.03 & Herbstgeschichte & 0 & $\leq 0.5$ \\
\hline DFF_3.01.35.04 & La parola Amore esiste $^{\text {a }}$ & 0 & $\leq 0.5$ \\
\hline DFF_3.01.35.16 & Leolo & 0 & $\leq 0.5$ \\
\hline DFF_50_500A & Bergbauern (Kurzfilm) ${ }^{a}$ & 0 & $\leq 0.5$ \\
\hline
\end{tabular}


Table 1. Cont.

\begin{tabular}{|c|c|c|c|}
\hline Owner/Code & Film Name & A-D Strip Level & $\begin{array}{c}\text { Acetic Acid } \\
\text { Concentration (ppm) }\end{array}$ \\
\hline \multicolumn{4}{|c|}{ Österreichische Akademie Der Wissenschaften } \\
\hline 88 & Der Bär & 1 & $1-2$ \\
\hline 90 & Die Spielwütigen Dose 1 & 3 & $>20$ \\
\hline 94 gr Rolle & & 0 & $\leq 0.5$ \\
\hline 96 & Der Monotype Satz & 0 & $\leq 0.5$ \\
\hline Carsta 62 & & 0 & $\leq 0.5$ \\
\hline Carsta 63 & & 1 & $1-2$ \\
\hline Carsta 64 & & 0 & $\leq 0.5$ \\
\hline Carsta 65 & & 0.5 & $0.5-1$ \\
\hline Film 99 & Memento & 3 & $>20$ \\
\hline SCS 00060-1 & FBI sucht Lemmy Caution & 1 & $1-2$ \\
\hline SCS 00060-4 & FBI sucht Lemmy Caution & 3 & $>20$ \\
\hline SCS 00060-5 & D FBI sucht Lemmy Caution Pos. Kopie Nr. 12 & 1.5 & $3-5$ \\
\hline SCS 00061-3 & Lemmy Caution schlägt zu & 3 & $>20$ \\
\hline SCS_00057A & Der 20. Juli 1944 & 3 & $>20$ \\
\hline SCS_00058A & Nordlicht & 2 & $6-8$ \\
\hline SCS_00059 & Deutsche Wochenschau & 3 & $>20$ \\
\hline SCS_00060-3 & FBI sucht Lemmy Caution & $2-2.5$ & $10-15$ \\
\hline
\end{tabular}

2.6. Analysis of Volatiles Released by Films Using Contact Solid-Phase Micro-Extraction (SPME) Coupled with Gas Chromatography /Mass Spectrometry (GC/MS)

A total number of 25 films, selected from those reported above as having different degradation and conservation status, based on the carrier material cellulose acetate were analyzed under controlled climatic storage conditions, using contact solid-phase microextraction (SPME) (Merck KGaA, Darmstadt, Germany) coupled with gas chromatography/mass spectrometry (GC/MS) (HP 5890, Hewlet Packard inc., Palo Alto, CA, USA; MSD 5972, Agilent Santa Clara, CA, USA; Column: ZB-5 HT, Zebron, Phenomex, Torrance, CA, USA).

The SPME techniques allows the sampling, extraction, concentration, and sample introduction into the column to be performed as a single step, without the need for organic solvent for sample extraction or complex procedures to calculate sample dilution and loss. This comparatively simple and efficient method, which has been widely used in different fields of analytical chemistry such as environmental and food analysis, is based on the extraction of solutes and volatiles from a sample matrix employing a highly absorptive polymeric layer coated onto a solid fused silica fiber. After a fixed exposure time of the fiber to the sample, equilibrium is reached between analytes in the matrix and analytes absorbed on the fiber and the extracted mass are, from this moment on, maximized and constant. The concentration of extracted analytes is thus proportional to their concentration in the sample. The SPME fiber with the absorbed analytes is directly inserted into the injection system of the gas chromatograph (GC), where the analytes desorb into the gas mobile phase (helium) which also acts as a carrier. In conjunction with the insertion of the fiber in the injector, the GC analysis is started.

The described method has been routinely used for gas chromatography (GC) and gas chromatography/mass spectrometry (GC/MS) analyses and successfully applied to a wide variety of compounds, especially for the extraction of volatile and semi-volatile organic compounds from industrial, environmental, biological and food samples [19], as well as for analyses of volatile compounds in the context of cultural heritage objects $[20,21]$.

Since the method is non-destructive, it can be applied to valuable original films, without damage or need of destructive sampling. Adapting the application of the method described in Lattuati et al. [20], in this particular case, the atmosphere was analyzed 
directly in the original film cans using divinylbenzol/carboxen/polydimethylsiloxane (DVB/CAR/PDMS) fibers, which were chosen to obtain general analysis results including polar analytes. The exposure time of the fibers was optimized to the analytes and, therefore, was determined to $24 \mathrm{~h}$ under a controlled climatic storage environment of $20{ }^{\circ} \mathrm{C}$ and $45 \%$ relative humidity (RH). GC/MS was performed with Agilent HP 5890/MSD 5972, Column: Zebron ZB-5 HT, 0.25 mm, He $1 \mathrm{~mL} / \mathrm{min}$. Injector Liner $1 \mathrm{~mm}$ i.D., Desorption of SPME-fibers $250{ }^{\circ} \mathrm{C}$. Oven: $2 \mathrm{~min}$ at $50{ }^{\circ} \mathrm{C}$, heating with $10^{\circ} / \mathrm{min}$ up to $300^{\circ} \mathrm{C}$. MSD Transfer Line $280^{\circ} \mathrm{C}$, Scan mode measurement: 10 to 650 units.

\subsection{Analysis Results and Findings}

The results obtained from the SPME-GC/MS measurements allow the analysis of off-gassing chemicals inside the closed original film boxes or cans and, therefore, can give essential findings about the composition of the atmosphere inside such a film box. The samples tested comprise several naturally aged historical film samples of various deterioration stages on cellulose acetate base, with different types of film materials (positive, negative, black and white, color).

The variety of out-gassing chemicals is large and inconsistent and reflects all aspects of the history of the individual film roll:

- Original composition;

- Chemicals used within the development process (to a minor extent);

- Storage conditions and their influences on chemical degradation;

- Actual deterioration stage;

- Treatment during use and long-time storage (e.g., influences from cleaning chemicals, chemicals added for preservation issues, etc.);

- Influence of long-time storage container (ventilated vs. non ventilated, inert materials vs. chemically reactive materials, etc.).

To a minor extent, the measurement process itself gives variations in results, due to the influence of the position of the SPME fiber, the RH and temperature during sampling.

Both factors were minimized to the best possible extent, e.g., $\mathrm{RH}$ and temperature were kept constant and stable for all measurements as well as for storage of the film samples (controlled and documented storage conditions, access storage, $20^{\circ} \mathrm{C} / 45 \% \mathrm{RH}$ ), and the fibers were positioned in close contact on similar and comparable positions on the respective film rolls.

As an example, the SPME-GC/MS chromatograms of two films are reported in Figures 1 and 2. The first figure shows the SPME-GC/MS chromatogram analysis results obtained from sample SCS-00060-5, cellulose acetate based black and white positive film, (manufacturer: Perutz, dated 1953) in a comparatively low deterioration stage (A-D strip level 1.5). Interestingly, phenol and camphor show high peaks, followed by the peak regions of alkanes and phthalates. A toluene peak is detected in the neighboring area.

Figure 2 shows the SPME-GC/MS chromatogram analysis results obtained from sample DFF_12_584, a $16 \mathrm{~mm}$ cellulose acetate based black and white positive film, in a low deterioration stage (A-D strip level 1.5-2). A butanol peak is detected in the direct neighboring area of acetic acid, and besides phenol and plasticizers (phthalates), a high amount of naphthalene was detected.

With cellulose acetate films, in many cases, some chemicals show higher peaks (and, therefore, higher levels, according to the semi-quantitative measuring method) than acetic acid. It is interesting to note that in several samples very high amounts of naphthalene were present, most probably a decomposition byproduct of diacetate films, where monochloronaphthalene was used as a plasticizer. It can also be assumed that naphthalene was used as insecticide, respectively as a protective chemical. 


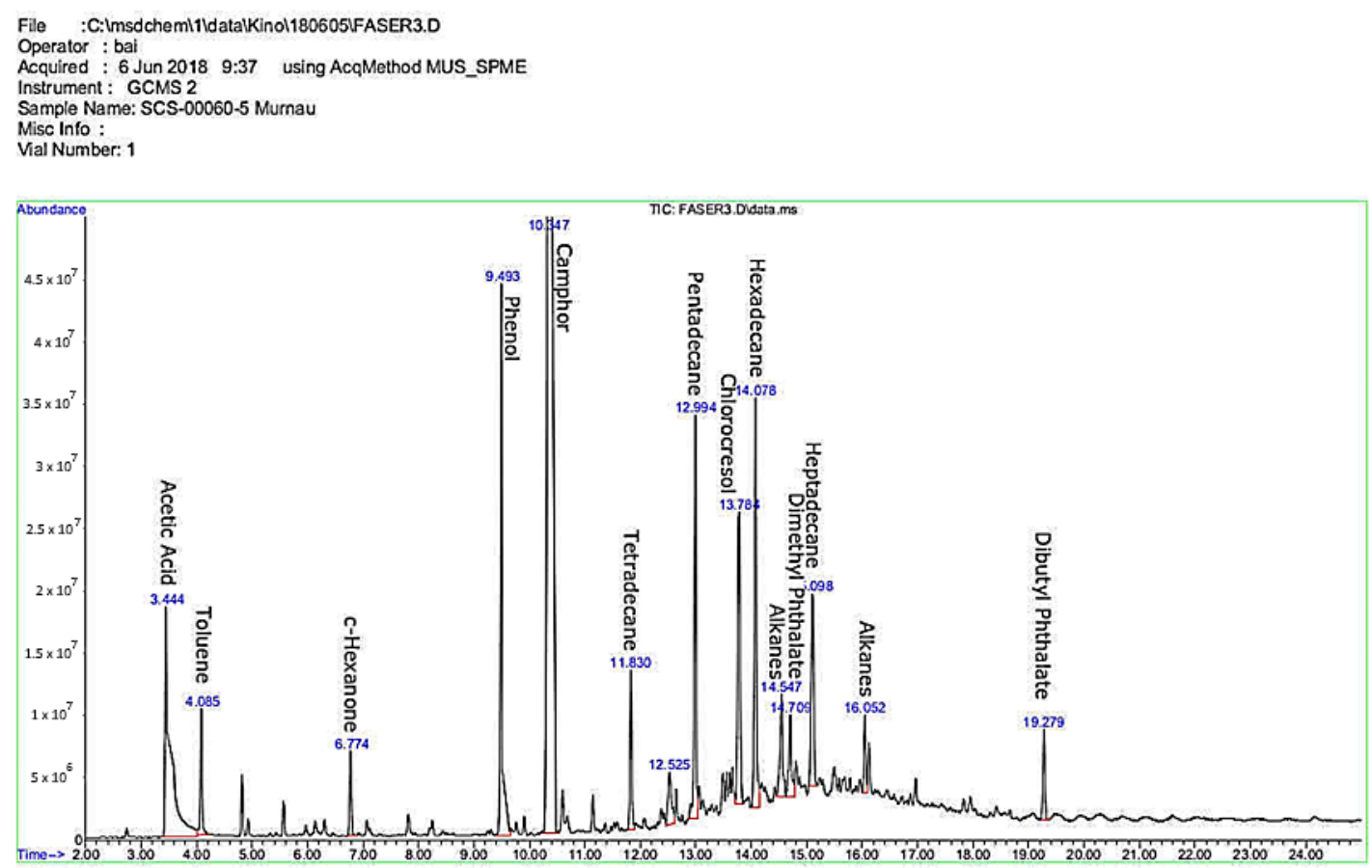

Figure 1. Solid-phase microextraction (SPME) coupled with gas chromatography/mass spectrometry (SPME-GC/MS) chromatogram analysis results obtained from sample SCS-00060-5, a 35 mm cellulose acetate-based black and white positive film.

File :C:Imsdcheml1datalKinol190121VFASER6.D

Acquired : 21 Jan 2019 15:02 using AcqMethod MUSSPME

Sample Name: Das Lied von der Nachtiga

Misc Info :

Vial Number: 6

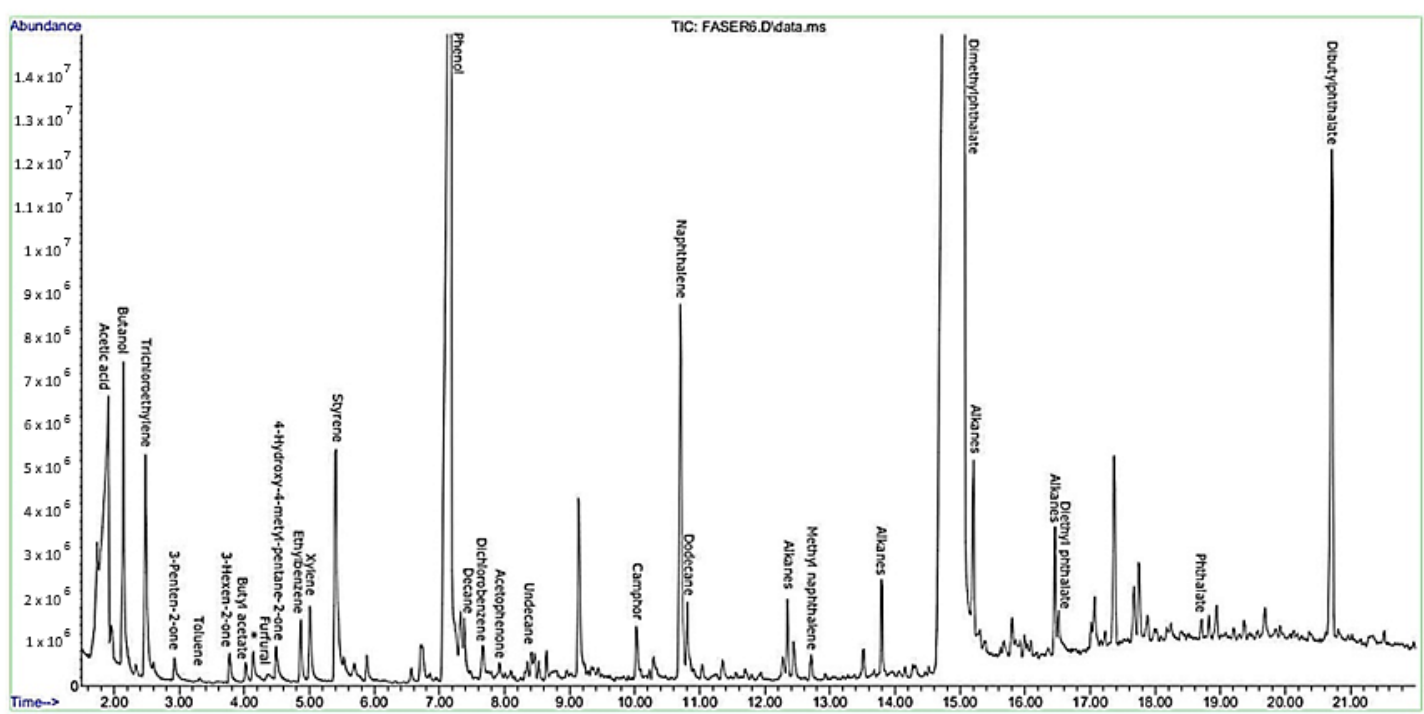

Figure 2. SPME-GC/MS chromatogram analysis results obtained from sample DFF_12_584, a $16 \mathrm{~mm}$ cellulose acetate based black and white positive film (manufacturer: Voigtlaender, dated 1943/44).

To summarize the results, a high and diverse variety of chemicals was detected. This fact is a very important finding, because in practice this means that film material of the same charge, manufacturer and period can be developed, stored, used, and treated differently during its history of use and, in combination with the numerous decomposition byproducts, therefore can evaporate different chemicals. The variety of the chemicals detected is large 
but can be categorized in main groups of acids (acetic acid, butanoic acid, hexanoic acid), alkanes, short chain alcohols, phenols, naphthalene, and phthalates.

\subsection{Sensors Positioning in Film Boxes}

In order to provide accurate, real-time data concerning the amount of acetic acid released by degrading films, the sensors should be put as close as possible to the cinematographic film. At the same time, to provide repeatable value, prevent cross-contamination and protect the sensors from mechanical damage by impact with the films, a significant distance and/or physical separation should be put between cinematographic film and sensors. In this work, we have tried to reconcile these two needs by producing two small holes on the top of the film container, through which the sensors were inserted to sample the air inside the box. An external structure, with minimized thickness, weight and integrating the Arduino board, anchored the sensors in place, providing power and acquiring the data, to be transmitted to the computer.

\section{Results}

\subsection{Selection of Gas Sensors}

To provide an accurate, real-time estimation of the amount of acetic acid accumulating during cellulose acetate films degradation, it was necessary firstly to identify the most common species released by the film during the degradation process. From literature sources [22-26], it was found that the average cellulose film degradation releases short organic acids (used for cellulose esterification, mainly acetic acid), various solvents using during the film manufacture, and residues of products used in conservation treatments (mainly butanol, used as antifungal treatment).

To define which vapors were most prominently emitted, cellulose acetate cinematographic films were analyzed by means of SPME-GC/MS. The results obtained are reported in Section 2.7. From the reported data it emerged that, as expected, the main marker of cellulose acetate film degradation is acetic acid, but other volatiles are also released, such as phenols, short chain alcohols, and naphthalene.

To the best of our knowledge, there are no commercial sensors currently available which are, at the same time, capable of quantifying acetic acid down to ppb level (as required to intervene before autocatalytic phenomena begin), do not respond to other volatiles released during film storage, and have extremely low space and power consumption requirements to make them suitable for long-term monitoring inside the boxes of historical cinematographic films To solve this problem, two sensors were selected, based on literature [27-29]: one showing higher response when exposed to acetic acid compared to other similar volatiles (such as trans-2-nonenal, pelargonic acid, diacetyl, butyl acetate, and n-decane), and a second one reported to be more selective towards short chain alcohols (such as ethanol, propanol, butanol). The first sensor will hereafter be identified as BIOS1 while the second will be identified as BIOS2.

\subsection{Sensor Thin Layer Analysis}

SEM, EDX and Raman analysis were performed on the surface of the chosen MOS sensors to understand if the different responses obtained depended on some different physic-chemical property of the MOS layers (i.e., layer thickness, layer surface roughness, metal oxide composing the thin layer).

Figure 3 demonstrates the SEM/EDX analysis and Raman spectroscopy of produced sensors. It is clearly seen that the surface of sample (a) has a very rough surface. EDX analysis shows the presence of $\mathrm{W}, \mathrm{O}$ and $\mathrm{C}$ in the film. The layer of $\mathrm{WO}_{3}$ consist of spherical nanoparticles with an average diameter about 100-150 nm. In order to study the phase composition of the produced sensors we used Raman spectroscopy. The Raman spectrum of the sample (a) indicates at least six modes at 93,141, 277, 336, 724, $813 \mathrm{~cm}^{-1}$ which correspond to $\mathrm{W}-\mathrm{W}$ bending, $\mathrm{O}-\mathrm{W}-\mathrm{O}$ bending and $\mathrm{O}-\mathrm{W}-\mathrm{O}$ stretching of monoclinic crystalline $\mathrm{WO}_{3}$ phases, respectively [30,31]. 

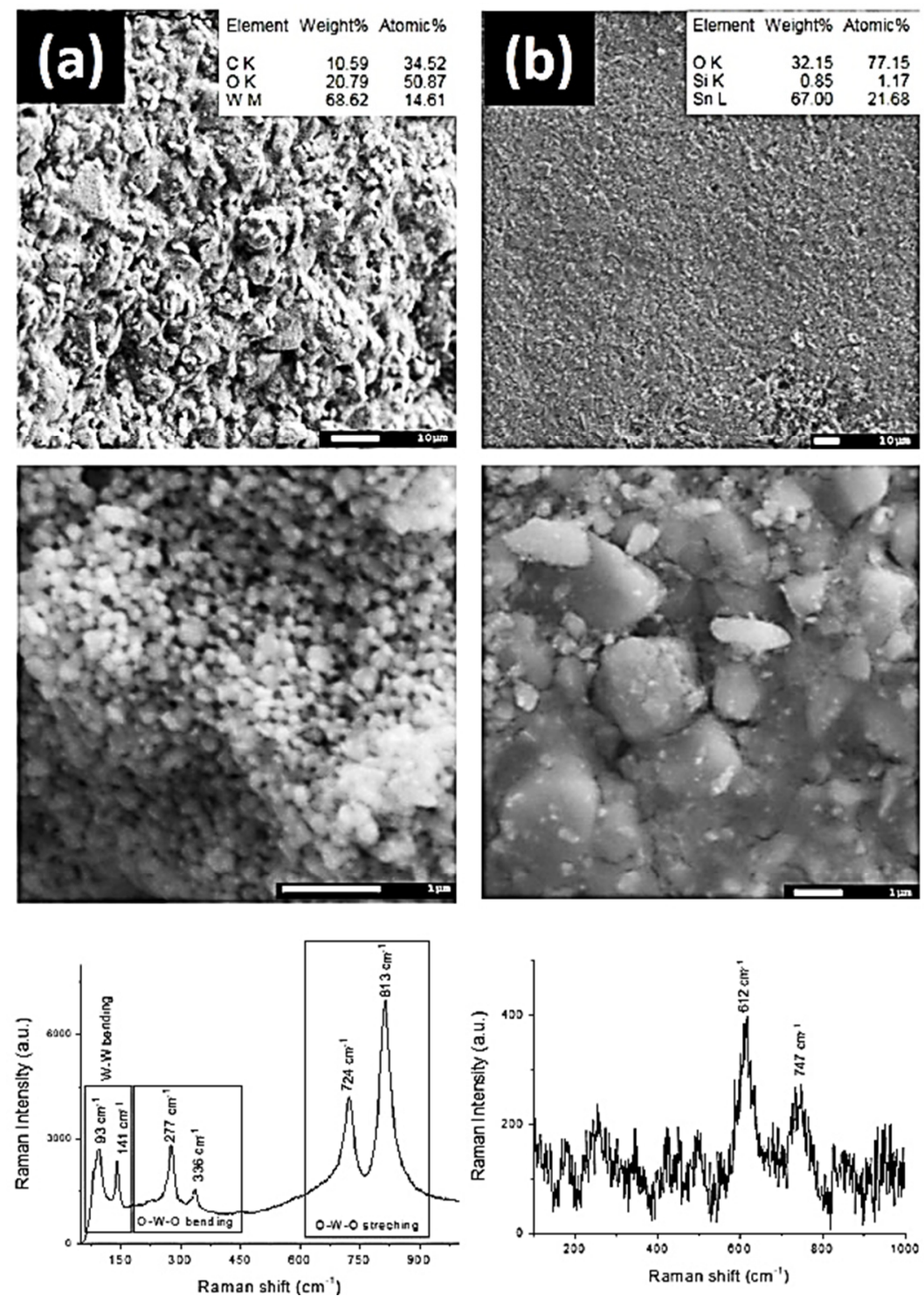

Figure 3. Scanning electron microscopy (SEM) analysis (inset-energy-dispersive X-ray spectra (EDX)) and Raman spectroscopy of samples BIOS1 (a) and BIOS2 (b).

The sample (b) is presented in the Figure $3 b$. It can be seen that the surface of the produced sensors is composed mostly of Sn and O. The surface is quite smooth; however, the highly magnified SEM images demonstrate that it consisted of micrometer crystalline blocks, which may be associated with a polycrystalline structure of the film. Raman spectroscopy confirmed this assumption. One may observe at least two weak peaks at 612 and $747 \mathrm{~cm}^{-1}$ corresponding to $\mathrm{TO}$ and $\mathrm{LO}$ Eu modes of $\mathrm{SnO}_{2}$, respectively [32,33].

\subsection{Sensors Response toward Target Gases}

As reported in Section 3.1, the MOS sensors BIOS1 and BIOS2 were chosen since the first had a more generic response, while the latter showed higher responses when exposed to short chain alcohols. These findings were further justified by the different composition and surface structure of the respective MOS layers, as seen in Section 3.2.

Since from SPME-GC/MS, it emerged that the most common vapor released by films, other than acetic acid, is butanol (data not shown) the sensor duplex responses towards acetic acid and butanol were investigated and are reported in Figure 4. 

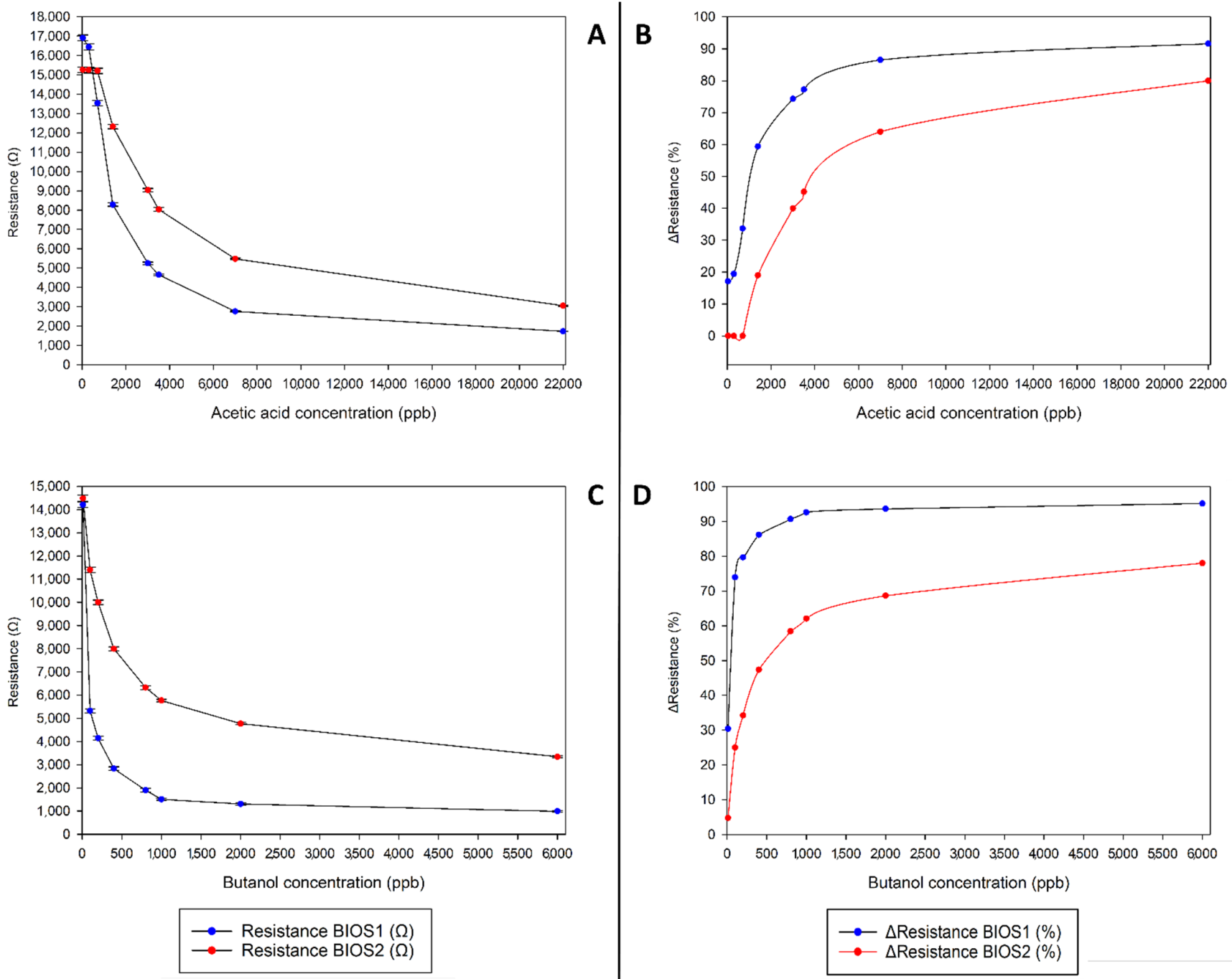

Figure 4. Response of BIOS1 and BIOS2 MOS sensors in terms of absolute resistance values when exposed to (A) acetic acid; (C) butanol. Obtained values are also reported in terms of percentage reduction compared to baseline when sensors are exposed to (B) acetic acid; (D) butanol. Each reported value is calculated as an average of three independent measures.

As can be seen, the two sensors show different response trends when exposed to the two target volatiles. BIOS1 seems to detect lower concentrations of acetic acid compared to BIOS2 and reaches saturation faster, while both sensors seem to be quite responsive to low concentrations of butanol.

It should be noted that neither of the two sensors show a linear range of response, having instead a response type more like negative exponential (or quasi-logarithmic for the curves reporting percentage reduction compared to baseline), which is common for resistive sensors like the ones employed in this work.

\subsection{Mathematical Data Processing and Acetic Acid Concentration Determination}

As reported in Section 3.3, sensors BIOS1 and BIOS2 respond both to acetic acid and butanol. It can be supposed that the resistance measured for each sensor, when they are exposed to an atmosphere containing both volatiles, will be a linear combination of the resistance variation for each gas. Thus, from a mathematical standpoint this can be expressed as:

$$
\left\{\begin{array}{l}
R_{\text {sper }}^{\text {Bios } 1}=\alpha\left(R_{A C}^{\text {Bios } 1}-R_{\text {but }}^{\text {Bios } 1}\right)+R_{\text {but }}^{\text {Bios } 1} \\
R_{\text {sper }}^{\text {Bios } 2}=\alpha\left(R_{A C}^{\text {Bios } 2}-R_{\text {but }}^{\text {Bios2 }}\right)+R_{\text {but }}^{\text {Bios } 2}
\end{array}\right.
$$


where $R_{\text {sper }}^{\text {Bios } 1}$, and $R_{\text {sper }}^{\text {Bios } 2}$ are the resistance values detected by the two sensors, $\alpha$ is the volume fraction of the acetic acid. $R_{A C}^{B i o s 1}, R_{b u t}^{B i o s 1}, R_{A C}^{B i o s 2}, R_{b u t}^{B i o s 2}$ are the calibration curves of BIOS1 and BIOS2, respectively, when exposed to Acetic acid (AC) or butanol (but). The calibrations curves obtained in Section 3.3 are approximated well by:

$$
\left\{\begin{array}{l}
R_{A C}^{\text {Bios } 1}=597,373 \cdot x_{A C}-0.592 \\
R_{b u t}^{\text {Bios } 1}=40,206 \cdot x_{b u t}-0.442 \\
R_{A C}^{\text {Bios } 2}=411,714 \cdot x_{A C}-0.484 \\
R_{b u t}^{\text {Bios } 2}=56,128 \cdot x_{b u t}-0.322
\end{array}\right.
$$

where $x_{A C}$ and $x_{b u t}$ are the concentration of each volatile species. Due to the complexity and non-linearity of the system obtained, machine-assisted numeric resolution is needed to solve it and accurately calculate the acetic acid concentration in a multiple volatiles mixture.

To solve this system, a software algorithm has been developed using an open-source mathematics-oriented syntax software called GNU Octave. The developed software takes as inputs the resistance values provided by the sensors and returns the total concentration of gases and the molar fraction of acetic acid, from which the acetic acid concentration can be calculated. To solve the system illustrated above, the developed algorithm uses the GNU Octave function vpasolve, which allows the resolution of the non-linear equation using a Newton-type algorithm. By rearranging the system as shown below in Equation (3):

$$
\left\{\begin{array}{c}
\left(R_{\text {sper }}^{\text {Bios } 1}-R_{b u t}^{\text {Bios } 1}\right) /\left(R_{A C}^{\text {Bios } 1}-R_{b u t}^{\text {Bios } 1}\right)=\left(R_{\text {sper }}^{\text {Bios }}-R_{b u t}^{\text {Bios } 2}\right) /\left(R_{A C}^{\text {Bios2 }}-R_{b u t}^{\text {Bios2 }}\right) \\
\alpha=\left(R_{\text {sper }}^{\text {Bios } 2}-R_{b u t}^{\text {Bios } 2}\right) /\left(R_{A C}^{\text {Bios } 2}-R_{b u t}^{\text {Bios } 2}\right)
\end{array}\right.
$$

Substituting the calibration curves obtained, shown in Equation (2), for the two sensors against each target volatile, we can write Equation (4):

$$
\left\{\begin{array}{c}
\left(R_{\text {sper }}^{\text {Bios } 1}-40,206 \cdot x^{-0.442}\right) /\left(597,373 \cdot x^{-0.592}-40,206 \cdot x^{-0.442}\right)=\left(R_{\text {sper }}^{\text {Bios }}-56,128 \cdot x^{-0.322}\right) /\left(411,714 \cdot x^{-0.484}-56,128 \cdot x^{-0.322}\right) \\
\alpha=\left(R_{\text {sper }}^{\text {Bios2 }}-56,128 \cdot x^{-0.322}\right) /\left(411,714 \cdot x^{-0.484}-56,128 \cdot x^{-0.322}\right)
\end{array}\right.
$$

The numerical solution of Equation (4) gives as output the total concentration of released volatiles and the volume fraction of acetic acid $\alpha$. It was previously seen that the two sensors only respond to acetic acid and butanol, and the two values $x$ and $\alpha$ can be put in a mathematical relationship, as shown in Equation (5):

$$
\left\{\begin{array}{c}
x=x_{A C}+x_{b u t} \\
\alpha=\frac{x_{A C}}{x}
\end{array}\right.
$$

The algorithm can thus, using Equations (4) and (5), calculate the concentration of acetic acid $\left(x_{A C}\right)$ and butanol $\left(x_{b u t}\right)$.

To solve a system and provide the acetic acid concentration, the algorithm needs about $5 \mathrm{~s}$ (depending on the hardware specifics of the machine on which it is operated and the complexity of the resulting system). The algorithm was tested on the raw data coming from mixtures of butanol and acetic acid at different concentrations, and it was found that the system has a limit of detection (LOD) for acetic acid of $30 \mathrm{ppb}$ and provided accurate responses for acetic acid concentrations up to $30 \mathrm{ppm}$.

To prove the initial supposition that resistance measured for each sensor, when they are exposed to an atmosphere containing both volatiles, will be a linear combination of the resistance variation for each gas, a test was conducted by exposing the two sensors different mixtures of acetic acid and butanol in a closed container. Tested mixtures and the results obtained are reported in Table 2. 
Table 2. Algorithm test on different acetic acid-butanol proportion in closed box to verify linearity of system. Each reported value is the average of algorithm calculations performed on three independent measurements.

\begin{tabular}{ccc}
\hline $\begin{array}{c}\text { Acetic Acid } \\
\text { Concentration (ppb) }\end{array}$ & $\begin{array}{c}\text { Butanol Concentration } \\
(\mathbf{p p b})\end{array}$ & $\begin{array}{c}\text { Acetic Acid Concentration } \\
\text { Determined by Algorithm (ppb) }\end{array}$ \\
\hline 1000 & 0 & $995 \pm 15$ \\
\hline 800 & 200 & $807 \pm 11$ \\
\hline 600 & 400 & $595 \pm 10$ \\
\hline 400 & 600 & $402 \pm 5$ \\
\hline 200 & 800 & $200 \pm 4$ \\
\hline 100 & 900 & $99 \pm 1$ \\
\hline 50 & 950 & $50 \pm 2$ \\
\hline 10 & 990 & $<30$ \\
\hline 0 & 1000 & $<30$ \\
\hline
\end{tabular}

From the data obtained it can be assumed that, even if BIOS1 and BIOS2 sensors' response to air containing both target analyte and interferent is not a perfect linear combination of the responses of each sensor towards each gas, it can be safely approximated using the linear model with minimal deviation between experimental and calculated acetic acid concentration values.

The algorithm has been integrated in the user interface software, called a BIOSENSOR Monitor. The BIOSENSOR Monitor recognizes the connection of the sensing array to the PC, identify which sensors are connected and in which slot and provides users with the data from each sensor both in numerical and graphical forms. If the sensors BIOS1 and BIOS2 are plugged in the board, the BIOSENSOR Monitor allows the user to read the raw resistance value provided by the sensors or, by pressing a button on its simple interface, to start the integrated algorithm, calculating and displaying the acetic acid concentration detected by the sensors.

\subsection{Test of Developed BIOS1 + BIOS2 Sensor Duplex on Real Samples and Validation with A-D Strips}

To demonstrate that the developed BIOS1 + BIOS2 sensor duplex can be successfully applied for automated real-time determination of acetic acid concentrations in film boxes, it was used to quantify the acetic acid vapor released by the film samples described in Section 2.5. For each measurement, the following protocol was employed:

- The BIOS1 + BIOS2 sensor duplex was placed on the top cover of a circular film box of fixed diameter, with the sensor reaching inside the container (see Section 2.8 Sensors positioning in film boxes) the material of which simulates those used in real storage conditions. The box was put in a refrigerator at $4{ }^{\circ} \mathrm{C}$, with controlled relative humidity at $50 \%$, to simulate the conditions used in conservation institutes for cinematographic films to simulate storage conditions used in conservation institutes

- The film to analyze was placed in the box, having care to not touch the sensors surfaces.

- The box was closed, and the data acquisition was started along with the data processing software.

- After 10 min (time required empirically determined as required for homogeneous diffusion of volatiles in the box and thus obtain stable values from the BIOS1 + BIOS2 duplex) acetic acid concentration was calculated from the acquired data.

The data obtained for each film, and the comparison with the acetic acid concentrations determined employing the official methodology (A-D strip placed in box with film for $24 \mathrm{~h}$ ) are reported in Table 3. 
Table 3. Comparison of acetic acid quantification results obtained employing official A-D strip method and developed metal oxide semiconductor (MOS) sensor array.

\begin{tabular}{|c|c|c|}
\hline Code & Result with A-D Strips (ppm) & Result with BIOS1-BIOS2 Sensor Array (ppm) \\
\hline Alinari sample 0 & $18.0-20.0$ & 17.03 \\
\hline Alinari sample 1 & $\leq 0.5$ & 0.455 \\
\hline Alinari sample 2 & $\leq 0.5$ & 0.362 \\
\hline Alinari sample 3 & $\leq 0.5$ & 0.493 \\
\hline Alinari sample 4 & $0.5-1.0$ & 0.884 \\
\hline Alinari sample 5 & $0.5-1.0$ & 0.94 \\
\hline Alinari sample 6 & $0.5-1.0$ & 0.92 \\
\hline Alinari sample 7 & $0.5-1.0$ & 1.00 \\
\hline Alinari sample 8 & $\leq 0.5$ & 0.383 \\
\hline Alinari sample 9 & $1.0-2.0$ & 1.86 \\
\hline Alinari sample 10 & $1.0-2.0$ & 1.91 \\
\hline Alinari sample 11 & $\leq 0.5$ & 0.477 \\
\hline Alinari sample 12 & $\leq 0.5$ & 0.475 \\
\hline Alinari-B/W photo films & $0.5-1.0$ & 0.815 \\
\hline Alinari-B/W photo reel & $1.0-2.0$ & 1.32 \\
\hline Alinari-red hue photo films & $0.5-1.0$ & 0.813 \\
\hline Alinari-color photo film & $0.5-1.0$ & 0.969 \\
\hline 00010820 & $>20$ & $>20$ \\
\hline 00011242 & $0.5-1.0$ & 1.034 \\
\hline 00015797 CulturArts 5 & $8-18$ & 11.981 \\
\hline 00015798 CulturArts 7 & $3-5$ & 2.560 \\
\hline 00015799 CulturArts 6 & $0.5-1.0$ & 0.597 \\
\hline 006113 & $0.5-1.0$ & 1.078 \\
\hline DFF_12_21 & $\leq 0.5$ & 0.679 \\
\hline DFF_12_556 & $\leq 0.5$ & 0.660 \\
\hline DFF_12_584 & $\leq 0.5$ & 0.255 \\
\hline DFF_3.01.35.01 & $\leq 0.5$ & $<0.030$ \\
\hline DFF_3.01.35.03 & $\leq 0.5$ & $<0.030$ \\
\hline DFF_3.01.35.04 & $\leq 0.5$ & $<0.030$ \\
\hline DFF_3.01.35.16 & $\leq 0.5$ & $<0.030$ \\
\hline DFF_50_500A & $\leq 0.5$ & 0.365 \\
\hline 88 & $1-2$ & 1.099 \\
\hline 90 & $>20$ & 37.540 \\
\hline 94 gr Rolle & $\leq 0.5$ & 0.417 \\
\hline 96 & $\leq 0.5$ & 0.290 \\
\hline Carsta 62 & $\leq 0.5$ & 0.722 \\
\hline Carsta 63 & $1-2$ & 1.614 \\
\hline Carsta 64 & $\leq 0.5$ & 0.382 \\
\hline Carsta 65 & $0.5-1$ & 0.864 \\
\hline
\end{tabular}


Table 3. Cont.

\begin{tabular}{ccc}
\hline Code & Result with A-D Strips (ppm) & Result with BIOS1-BIOS2 Sensor Array (ppm) \\
\hline Film 99 & $>20$ & $>20$ \\
\hline SCS 00060-1 & $1-2$ & 1.687 \\
\hline SCS 00060-4 & $>20$ & 520 \\
\hline SCS 00060-5 & $3-5$ & $>20$ \\
\hline SCS 00061-3 & $>20$ & $>20$ \\
\hline SCS_00057A & $>20$ & 6.277 \\
\hline SCS_00058A & $6-8$ & $>20$ \\
\hline SCS_00059 & $>20$ & 13.085 \\
\hline SCS_00060-3 & $10-15$ & \\
\hline
\end{tabular}

After each measurement, the sensor was exposed to clean fresh air (no forced ventilation required) and the signal from both BIOS1 and BIOS2 sensors went back to baseline levels in less than $5 \mathrm{~min}$.

The good agreement obtained between data from A-D strips and acetic acid concentration calculated with the developed algorithm confirms that butanol is the only interfering vapor among those released by degrading cellulose acetate cinematographic films.

As can be seen from Table 3, the results obtained with the developed array fit very well with those obtained employing the official method.

\subsection{BIOS1 + BIOS2 Sensor Duplex Long-Term Stability under Continuous Exposure to Cinematographic Films Vapors}

To evaluate the stability of the selected sensors when continuously exposed to the vapors released by the cinematographic films, a test was conducted by leaving six films in six different boxes, each with its own BIOS1 + BIOS2 sensor duplex installed. Acetic acid concentrations were measured at the start of the test, after 15 days and after 30 days. The results obtained are reported in Table 4 .

Table 4. Acetic acid values calculated at test start, after 15 days and 30 days of continuous exposure of BIOS1 + BIOS2 sensor duplex to vapors released by real cinematographic film samples.

\begin{tabular}{cccc}
\hline \multirow{2}{*}{ Film Name } & \multicolumn{2}{c}{ Acetic Acid Concentrations (ppb) at Elapsed Time } \\
\cline { 2 - 4 } & Day 0 & Day 15 & Day 30 \\
\hline Film 90 & $37,540 \pm 703$ & $37,150 \pm 751$ & $37,990 \pm 720$ \\
\hline Film 88 & $1100 \pm 29$ & $1063 \pm 32$ & $1107 \pm 32$ \\
\hline Film 94 & $428 \pm 8$ & $414 \pm 6$ & $418 \pm 5$ \\
\hline Film 96 & $287 \pm 2$ & $290 \pm 1$ & $290 \pm 1$ \\
\hline Carsta 64 & $380 \pm 9$ & $369 \pm 11$ & $382 \pm 7$ \\
\hline Carsta 65 & $875 \pm 19$ & $864 \pm 21$ & $886 \pm 20$ \\
\hline
\end{tabular}

From the data reported, no significant variations are detected in the acetic acid concentrations calculated in the examined period.

\section{Discussion}

The sensor duplex has been developed to provide a competitive system for the early detection of the acetic acid released during the degradation of cinematographic films produced using cellulose acetate. As mentioned in the introduction, this material's degradation process consists of two phases: an initial one, which is water-dependent, the kinetic of which is quite slow. Once the concentration of acetic acid reaches a certain concentration in air, an autocatalytic process triggers, which quickly leads to irreversible damage to the film. 
It is thus fundamental to detect the release of acetic acid from the cinematographic films as soon as possible in order to apply safekeeping techniques.

The developed sensor duplex proved reliable for the accurate quantification of acetic acid among all the volatiles released during cinematographic films degradation. This was possible thanks to the selection of the two MOS sensors, one based on tungsten oxide, the other based on tin oxide. It is known from literature [34] that MOS sensors employing $\mathrm{SnO}_{2}$ as thin layer are responsive towards oxidable vapors, particularly alcohols. This is due to the formation of an oxygen layer in proximity with the $\mathrm{SnO}_{2}$ particles. This interaction causes a shift in the electron distribution in the $\mathrm{SnO}_{2}$ particles, with consequent variation of the conductivity of the thin layer. When an oxidable gas is introduced in the system, oxygen leaves the proximity of the tin oxide particles to oxidize the gas, causing a reorganization of the electrons in the tin oxide particles, with consequent resistance variation. On the other hand, tungsten oxide thin films do not show these phenomena [35], proving responsive to both oxidizing and reducing gasses.

In the examined case, the two compounds that influenced the response of the employed sensors were 1-butanol (an oxidable vapor) and acetic acid (a vapor without marked oxidizing or reducing properties). The chosen sensors responded to both gases but with markedly different profiles. When exposed to butanol, the tin oxide sensor recorded a reduction of $90 \%$ of resistance when exposed to $1 \mathrm{ppm}$, while when exposed to acetic acid it showed a similar reduction only when exposed to concentrations exceeding $20 \mathrm{ppm}$. On the other hand, the tungsten oxide sensor shows an overall lower decrease of resistance, reaching a $60 \%$ decrease when exposed to $1 \mathrm{ppm}$ of butanol or when exposed to 6 ppm of acetic acid.

The developed mathematical system leverages these different resistance reduction profiles in order to accurately calculate the acetic acid concentration in a mixed gas system employing the resistance values provided by the two sensors. In this way, it was possible to achieve a LOD for acetic acid of $30 \mathrm{ppb}$, after an exposition time of the sensors to the vapor mixture of only $10 \mathrm{~min}$. The system proved to be stable even under constant exposition to the released gases: after 1 month of exposition, the results remained constant with less than $3 \%$ overall variation.

The currently used method to evaluate the acetic acid released by films in conservation institutes are A-D strips. These are small paper strips, imbibed with a $\mathrm{pH}$-sensitive dye which initially is blue and progressively turns first green, then orange-yellow when exposed to increasing concentrations of acetic acid. In order to provide an accurate measurement, A-D strips need to be put in intimate contact with the film for a period of time depending on the storage temperature (at least $24 \mathrm{~h}$ at room temperature, 3 weeks or more if stored in a refrigerated room at $4{ }^{\circ} \mathrm{C}$ ). For historical archives, where there is a need to monitor thousands to hundreds of thousands of independently stored film rolls, this means having a large staff dedicated solely to periodically checking and changing the strips. Furthermore, being a colorimetric method based on naked eye comparison with a provided reference, it may be affected by subjective interpretation and/or recognition of the color change, which may lead to false alarms or tardy action. A well-trained staff could theoretically recognize variations in the color change of A-D strips corresponding to acetic acid concentrations of $500 \mathrm{ppb}$ but, usually, it is difficult to reliably detect concentrations lower than $1 \mathrm{ppm}$.

On the other hand, the developed MOS sensor duplex has a limit of detection for acetic acid of $30 \mathrm{ppb}$, which is independent of human subjectivity. Furthermore, the MOS sensor can provide an accurate evaluation of the acetic acid concentration after only 15 min since the introduction of the film in the box. Further measurements, require even shorter time (about $5 \mathrm{~min}$ ), needed for the warm-up of the MOS sensor. Having both the sensors and the Arduino processing unit integrated in the film box allows for periodic measurements on the cinematographic film, without need for human intervention and a consequent risk of human exposure to the gases accumulating in the film box. Finally, the system can be fully automatized by connecting the Arduino boards using cables to a central unit, from which the state of all cinematographic films subjected to monitoring can be checked. In Figure 5, a 
comparison of the (theoretical) LOD for A-D strips and the LOD of the developed MOS sensor duplex is illustrated.

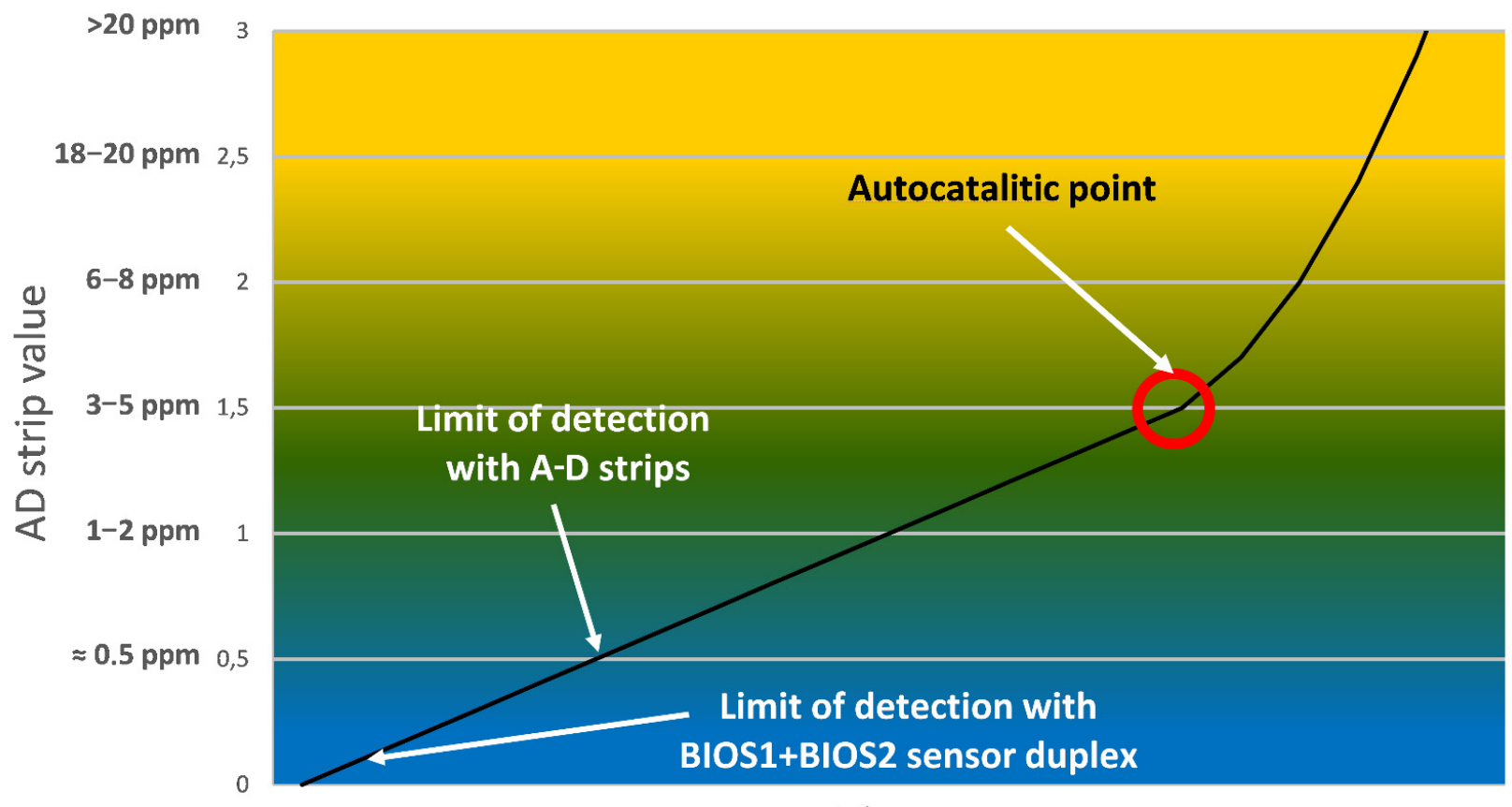

\section{Time}

Figure 5. Comparison of detection limits between commonly used method for evaluation of degradation level of cinematographic films (A-D strips) and the developed BIOS1 + BIOS2 sensor duplex.

\section{Conclusions}

In this work, metal oxide semiconducting (MOS) sensors were integrated to an Arduino board to assemble an array capable of selectively quantifying acetic acid released by films undergoing degradation, regardless of the presence of other volatiles. To do so, different MOS-based sensors have been tested and two were selected for being responsive only to acetic acid and butanol, each with its own calibration curve. An algorithm was devised which uses the calculated calibration curves to precisely determine the acetic acid concentration in butanol-acetic acid mixtures. The system demonstrated a LOD for acetic acid of $30 \mathrm{ppb}$ and an upper limit of detection of $30 \mathrm{ppm}$. Finally, the sensor duplex with the developed algorithm was used to quantify the acetic acid released by a total of 48 film samples, made of cellulose acetate or other supporting materials. The results obtained were validated using the acetic acid concentrations found with the official method (A-D-strips). It is possible to foresee an application of the described system as an early-warning tool for incipient degradation of cellulose acetate-based films in archives.

Author Contributions: Conceptualization, M.T.G. and D.Z.; methodology, J.B., G.V. and D.Z.; software, G.V.; validation, G.V. and D.Z.; formal analysis, G.V. and I.I.; investigation, I.I., J.B., G.V. and D.Z.; resources, M.T.G. and N.W.; writing-original draft preparation, D.Z.; writing-review and editing, D.Z.; supervision, M.T.G.; project administration, M.T.G.; funding acquisition, M.T.G. All authors have read and agreed to the published version of the manuscript.

Funding: This research has received funding from the European Union's Horizon 2020 Program: NMBP-35-2017-Innovative solutions for the conservation of 20th century cultural heritage (Grant agreement ID: 760801), and MSCA-RISE-2017-Research and Innovation Staff Exchange H2020EU.1.3.3-Grant agreement ID: 778157 (CanBioSe).

Informed Consent Statement: Not applicable.

Data Availability Statement: Part of the data presented in this study are available on request from the corresponding author. The data are not publicly available due to "Non-disclosure agreements" between authors. 


\begin{abstract}
Acknowledgments: We would like to thank NEMOSINE project partners and heritage institutions Deutsches Filminstitut \& Filmmuseum, Institut Valencià De Cultura (Filmoteca Valenciana), Österreichische Akademie der Wissenschaften and Andrea de Polo of Fondazione Alinari per la Fotografia 2018 for providing the film samples used in this work. Furthermore, we would like to thank all NEMOSINE partners for the precious discussions and information exchanges concerning film conservation and degradation that led to the results here published.
\end{abstract}

Conflicts of Interest: The authors declare no conflict of interest. The funders had no role in the design of the study; in the collection, analyses, or interpretation of data; in the writing of the manuscript, or in the decision to publish the results.

\title{
References
}

1. Puls, J.; Wilson, S.A.; Hölter, D. Degradation of Cellulose Acetate-Based Materials: A Review. J. Polym. Environ. 2011, 19, 152-165. [CrossRef]

2. Quye, A.; Littlejohn, D.; Pethrick, R.A.; Stewart, R. Investigation of Inherent Degradation in Cellulose Nitrate Museum Artefacts. Polym. Degrad. Stab. 2011, 96, 1369-1376. [CrossRef]

3. Ahmad, I.R.; Cane, D.; Townsend, J.H.; Triana, C.; Mazzei, L.; Curran, K. Are We Overestimating the Permanence of Cellulose Triacetate Cinematographic Films? A Mathematical Model for the Vinegar Syndrome. Polym. Degrad. Stab. 2020, $172,109050$. [CrossRef]

4. Malm, C.J.; Fordyce, C.R.; Tanner, H.A. Properties of Cellulose Esters of Acetic, Propionic, and Butyric Acids. Ind. Eng. Ghent. 1942, 34, 430. [CrossRef]

5. Yadav, N.; Hakkarainen, M. Degradable or Not? Cellulose Acetate as a Model for Complicated Interplay between Structure, Environment and Degradation. Chemosphere 2021, 265, 128731. [CrossRef]

6. Fordyce, C.R.; Meyer, I.W.A. Plasticizers for Cellulose Acetate and Cellulose Acetate Butyrate. Ind. Eng. Chem. 1940, 8, 142. [CrossRef]

7. Charvet, A.; Vergelati, C.; Long, D.R. Mechanical and Ultimate Properties of Injection Molded Cellulose Acetate/Plasticizer Materials. Carbohydr. Polym. 2019, 204, 182-189. [CrossRef]

8. Kemper, B.; Lichtblau, D.A. Extraction of Plasticizers: An Entire and Reproducible Quantification Method for Historical Cellulose Acetate Material. Polym. Test. 2019, 80, 106096. [CrossRef]

9. Da Ros, S.; Aliev, A.E.; del Gaudio, I.; King, R.; Pokorska, A.; Kearney, M.; Curran, K. Characterising Plasticised Cellulose Acetate-Based Historic Artefacts by NMR Spectroscopy: A New Approach for Quantifying the Degree of Substitution and Diethyl Phthalate Contents. Polym. Degrad. Stab. 2021, 183, 109420. [CrossRef]

10. Ram, A.T.; Kopperl, D.F.; Sehlin, R.C.; Morris, S.M.K.; Vincent, J.L.; Miller, P. The Effects and Prevention of the “Vinegar Syndrome". J. Imaging Sci. Technol. 1994, 38, 249-261.

11. Al Mohtar, A.; Nunes, S.; Silva, J.; Ramos, A.M.; Lopes, J.; Pinto, M.L. First-Principles Model to Evaluate Quantitatively the Long-Life Behavior of Cellulose Acetate Polymers. ACS Omega 2021, 6, 8028-8037. [CrossRef] [PubMed]

12. Al Mohtar, A.; Pinto, M.L.; Neves, A.; Nunes, S.; Zappi, D.; Varani, G.; Ramos, A.M.; Melo, M.J.; Wallaszkovits, N.; Lahoz Rodrigo, J.I.; et al. Decision Making Based on Hybrid Modeling Approach Applied to Cellulose Acetate Based Historical Films Conservation. Sci. Rep. 2021, 11, 16074. [CrossRef] [PubMed]

13. Nicholson, C.; O'Loughlin, E.M. The Use of A-D Strips for Screening Conservation and Exhibit Materials. Available online: https:/ / cool.culturalheritage.org/coolaic/sg/bpg/annual/v15/bp15-11.html (accessed on 30 November 2020).

14. Townsend, J.H.; Hackney, S.; Kearney, M. A Critical Assessment of A-D Strips®Used in Degradation Studies of Artworks Made from Cellulose Acetate. Stud. Conserv. 2021, 2, 91. [CrossRef]

15. Zhou, Y.; Wang, Y.; Wang, Y.; Yu, H.; Zhang, R.; Li, J.; Zang, Z.; Li, X. MXene $\mathrm{Ti}_{3} \mathrm{C}_{2} \mathrm{~T}_{x}$-Derived Nitrogen-Functionalized Heterophase $\mathrm{TiO}_{2}$ Homojunctions for Room-Temperature Trace Ammonia Gas Sensing. ACS Appl. Mater. Interfaces 2021, 13, 56485-56497. [CrossRef] [PubMed]

16. Wang, Y.; Zhou, Y.; Wang, Y.; Zhang, R.; Li, J.; Li, X.; Zang, Z. Conductometric Room Temperature Ammonia Sensors Based on Titanium Dioxide Nanoparticles Decorated Thin Black Phosphorus Nanosheets. Sens. Actuators B Chem. 2021, $349,130770$. [CrossRef]

17. Zappi, D.; Ramma, M.M.; Scognamiglio, V.; Antonacci, A.; Varani, G.; Giardi, M.T. High-Tech and Nature-Made Nanocomposites and Their Applications in the Field of Sensors and Biosensors for Gas Detection. Biosensors 2020, 10, 176. [CrossRef]

18. Image Permanence Institute ${ }^{\circledR}$ (IPI). User's Guide for A-D Strips ${ }^{\circledR}$ _Film Base Deterioration Monitors. 2016. Available online: https://www.filmcare.org/pdf/adstrips_instructions.pdf (accessed on 2 December 2020).

19. Kusch, P. The Application of Headspace: Solid-Phase Microextraction (HS-SPME) Coupled with Gas Chroma-Tography/Mass Spectrometry (GC/MS) for the Characterization of Polymers. In Gas Chromatography: Analysis, Methods and Practices; Biochemistry Research Trends; Nova Science Publishers, Inc.: New York, NY, USA, 2017; pp. 69-103. ISBN 978-1-5361-1990-9.

20. Lattuati-Derieux, A.; Bonnassies-Termes, S.; Lavédrine, B. Identification of Volatile Organic Compounds Emitted by a Naturally Aged Book Using Solid-Phase Microextraction/Gas Chromatography/Mass Spectrometry. J. Chromatogr. A 2004, 1026, 9-18. [CrossRef] 
21. Kearney, M.; Parkin, I.; Townsend, J.H.; Hidalgo, M.; Curran, K. Characterisation of VOCs Surrounding Naum Gabo's Construction in Space 'Two Cones', (Tate) by in Situ SPME GC-MS Monitoring. Stud. Conserv. 2018, 63, 369-371. [CrossRef]

22. Reilly, J.M. IPI Storage Guide for Acetate Film; Image Permanence Institute [IPI]: Rochester, NY, USA, 1993.

23. Reilly, J.A. Celluloid Objects: Their Chemistry and Preservation. J. Am. Inst. Conserv. 1991, 30, 145-162. [CrossRef]

24. Adelstein, P.Z.; Reilly, J.M.; Nishimura, D.W.; Erbland, C.J. Stability of Cellulose Ester Base Photographic Film: Part I-Laboratory Testing Procedures. SMPTE J. 1992, 101, 336-346. [CrossRef]

25. Liu, L.; Gong, D.; Bratasz, L.; Zhu, Z.; Wang, C. Degradation Markers and Plasticizer Loss of Cellulose Acetate Films during Ageing. Polym. Degrad. Stab. 2019, 168, 108952. [CrossRef]

26. Kammer, J.; Truong, F.; Boissard, C.; Soulié, A.-L.; Dupont, A.-L.; Simon, L.; Gros, V.; Lavédrine, B. Quantitative and Qualitative Assessment of VOCs Emitted from Cellulose Acetate Movie Films by PTR-ToF-MS. J. Cult. Herit. 2021, 47, 50-58. [CrossRef]

27. Gancarz, M.; Nawrocka, A.; Rusinek, R. Identification of Volatile Organic Compounds and Their Concentrations Using a Novel Method Analysis of MOS Sensors Signal. J. Food Sci. 2019, 84, 2077-2085. [CrossRef] [PubMed]

28. Itoh, T.; Koyama, Y.; Shin, W.; Akamatsu, T.; Tsuruta, A.; Masuda, Y.; Uchiyama, K. Selective Detection of Target Volatile Organic Compounds in Contaminated Air Using Sensor Array with Machine Learning: Aging Notes and Mold Smells in Simulated Automobile Interior Contaminant Gases. Sensors 2020, 20, 2687. [CrossRef]

29. Fonollosa, J.; Fernández, L.; Huerta, R.; Gutiérrez-Gálvez, A.; Marco, S. Temperature Optimization of Metal Oxide Sensor Arrays Using Mutual Information. Sens. Actuators B: Chem. 2013, 187, 331-339. [CrossRef]

30. Djaoued, Y.; Balaji, S.; Brüning, R. Electrochromic Devices Based on Porous Tungsten Oxide Thin Films. J. Nanomater. 2012, 2012, e674168. [CrossRef]

31. Wenderich, K.; Noack, J.; Kärgel, A.; Trunschke, A.; Mul, G. Effect of Temperature and PH on Phase Transformations in Citric Acid Mediated Hydrothermal Growth of Tungsten Oxide. Eur. J. Inorg. Chem. 2018, 2018, 917-923. [CrossRef]

32. Diéguez, A.; Romano-Rodríguez, A.; Vilà, A.; Morante, J.R. The Complete Raman Spectrum of Nanometric SnO 2 Particles. J. Appl. Phys. 2001, 90, 1550-1557. [CrossRef]

33. Elger, A.-K.; Hess, C. Application of Raman Spectroscopy to Working Gas Sensors: From in Situ to Operando Studies. Sensors 2019, 19, 5075. [CrossRef]

34. Kong, Y.; Li, Y.; Cui, X.; Su, L.; Ma, D.; Lai, T.; Yao, L.; Xiao, X.; Wang, Y. SnO 2 Nanostructured Materials Used as Gas Sensors for the Detection of Hazardous and Flammable Gases: A Review. Nano Mater. Sci. 2021, 5, 16. [CrossRef]

35. Zheng, H.; Ou, J.Z.; Strano, M.S.; Kaner, R.B.; Mitchell, A.; Kalantar-Zadeh, K. Nanostructured Tungsten Oxide-Properties, Synthesis, and Applications. Adv. Funct. Mater. 2011, 21, 2175-2196. [CrossRef] 